\title{
The Implementations of Suitable Cutting Parameters by Grinding of Titanium VT9 with Im- pact on Surface Integrity
}

\author{
Dana Stancekova $^{1}$, Anna Rudawska $^{2}$, Miroslav Neslušan $^{1}$, Jozef Mrázik ${ }^{1}$, Miroslav Janota ${ }^{1}$ \\ ${ }^{1}$ University of Zilina, Faculty of Mechanical Engineering, Univerzitna 1, 010 26, Zilina, Slovak Republic, E-mail: \\ dana.stancekova@fstroj.uniza.sk, \\ ${ }^{2}$ Lublin University of Technology, Faculty of Mechanical Engineering, Nadbystrzycka 36, 20-618 Lublin, Poland, E- \\ mail: a.rudawska@pollub.pl
}

\begin{abstract}
Despite the fact that Titanium alloys are frequently used in medicine, aviation industry and also in machine manufacture due to their strength and resistance against external influences. Moreover, their innovation to obtain better and more suitable parameters still proceeds. Regarding their mechanical properties, they are considerably less machinable which affects surface integrity of a machined area. That is why a proper selection of a machine tool and cutting conditions are extremely important. This paper deals with a finishing grinding process of the material VT9 by means of specific grinding wheels 5TG and DIA under specified cutting conditions. Based on experimental verifications it can be defined which grinding Wheel is more suitable in specific conditions with an impact on integrity of the ground surface. From the standpoint of grinding parameters such as surface roughness, thermal impact and acting of cutting forces as well as arising residual stress in the surface layer are key for surface integrity.
\end{abstract}

Keywords: Grinding, Cutting forces, surface roughness, residual stress

\section{Introduction}

One of the fastest and dynamically developing industries is medicine which deals especially with the production of orthopaedic implants and prosthetic devices. Approximately 90 per cent of components for implants are produced from titanium alloys. An increase of implants is recorded every year and a main reason is an increasing age limit of the population. This is the reason to prepare in time and thus secure suitable Technologies for machining of titanium alloys.

Titanium alloys are less machinable than steels of the same strength and hardness due to their mechanical and metallurgical characteristics. Titanium alloy components will increase in the medical industry as well as in the aviation in aircraft engine production and in the production of construction components. Recently titanium application has been found also in an area of consumer goods and sports equipment thanks to aesthetic aspects and luxurious feelings.

Compared with other machining processes that include chip production, grinding by grinding wheels is always and important and potential machining process for component production with an aim to obtain better dimension tolerances and surface quality $[1,2]$.

Several experts and professionals from various universities have dealt with the research of surface integrity of titanium and its alloys, e.g., Ulutan D, Ozel T [3], Jackson MJ, Davis CJ, Hitchiner MP, Mills B [4], Yao CF, Jin QC, Huang XC, Wu DX, Ren JX, Zhang DH [5], Bigerelle et al. [6,7] and they have proposed in their research of surface integrity by grinding of titanium alloys a way of characterization of surface roughness in the process of tool wear and for a characterization of surface integrity, dynamics of processing and mechanical properties a series of parameters of the process of roughness have been applied.
Bhaumik et al. [8] found that about $60 \%$ of the in-service faults of aerospace components are caused by fatigue, and the surface integrity characteristics, such as residual stress, have a great influence on the fatigue life of aeronautics and spaceflight components. It is very important to explore the influence law guiding engineering practice [9].

Problems that we deal with when machining of titanium alloys are known and not just few. Titanium alloys react more as badly machinable stainless steels, but they show even higher toughness. When machined, a strong strengthening of the surface layer occurs. Therefore, one must apply suitable parameters when grinding. [10, 11]

Grinding machines and tools develop fast and they reach a high-quality level and efficiency. Grinding is not just a mere finishing operation, but it is a type of production machining.

Several aspects affect surface quality such as surface roughness, cutting forces and heat released by machining. That results in high residual stresses and thus deterioration of the machined surface. To prevent high stresses by machining and high surface roughness we intend to reach the most suitable grinding parameters by means of possible measurements that will help us in a grinding process to improve more and to obtain the best possible results. $[12,13]$

\section{Experimental verifications}

\section{Machined material}

Titanium is a metal with a still wider range of applications in various areas of technology and everyday life. Pure titanium and its alloys belong among materials for specific purposes. It has high strength, almost as steel. It is lighter by $45 \%$ than steel. It is paramagnetic and it has low thermal and magnetic conductivity and it is corrosion resistant 
There occurs a thin transparent layer of oxide on titanium when it contacts oxygen and it does not react with any substances and therefore it is resistant against most of acids and sea water. A great disadvantage is its very expensive way of production from rocks which is mirrored in its cost. It is approximately five times more expensive than stainless steel. Titanium is not toxic for people and it does not cause allergies. That is why artificial joints and tooth implants are made from it and we can find its applications in military technology (submarine construction, airplanes, etc.), but also in tennis rockets, jewellery, frames of glasses, ski poles, clocks and articles of daily use. [14]

Tab. 1 The chemical composition of ground samples VT9 [wt. \%]

\begin{tabular}{|c|c|c|c|c|c|c|}
\hline & $\mathrm{Al}$ & V & Mo & Sn & $\mathrm{Zr}$ & $\mathrm{Cr}$ \\
\hline$\%$ & 7.24401 & $<0.043270$ & 2.24871 & 0.015351 & $<0.001307$ & 1.27748 \\
\hline & $\mathrm{Pd}$ & $\mathrm{Nb}$ & $\mathrm{Mn}$ & Co & $\mathrm{Ni}$ & $\mathrm{Cu}$ \\
\hline$\%$ & 0.02376 & $<0.001252$ & $<0.009282$ & $<0.003707$ & $<0.003002$ & $<0.002183$ \\
\hline & $\mathrm{Fe}$ & Ru & $\mathrm{Pb}$ & $\mathrm{Cd}$ & $\mathrm{Si}$ & $\mathrm{Ti}$ \\
\hline$\%$ & 0.347416 & 0.011401 & $<0.008308$ & 0.020187 & 0.105870 & 88.7140 \\
\hline
\end{tabular}

In general titanium has:

- - excellent corrosion resistance,

- - very good erosion resistance (when welding with a frequently applied metals),

- - very high compatibility with animal tissues (surgical implants),

- - a lower model of tensile stress than steel materials, a higher melting point, a lower coefficient of heat conductivity. [15]

\section{Impact of cutting forces}

Experimental samples were ground by the grinder BPH $21 \mathrm{NA}$ at the speed $n=2850 \mathrm{~min}^{-1}$ with the feed $a_{p}$ $=0.005 ; 0.01 ; 0.015 ; 0.02 \mathrm{~mm}$ with the application of the metalworking fluid Emulzin $\mathrm{H}$ - $2 \%$ concentration, the flow 8 litres per 1 minute. Applied wheels: 5TG 60J9V (50\% profile TG grains, $50 \% \mathrm{Al}_{2} \mathrm{O}_{3}$ ) and the diamond wheel D76-K100 B-III.

To find components of the cutting force by the process of grinding we used the dynamometer KISTLER TYPE 9273 (Fig. 1.). We recorded the values of measurements into the computer (Fig. 2) and the measured data were processed by means of the programme DASYLab 8.0

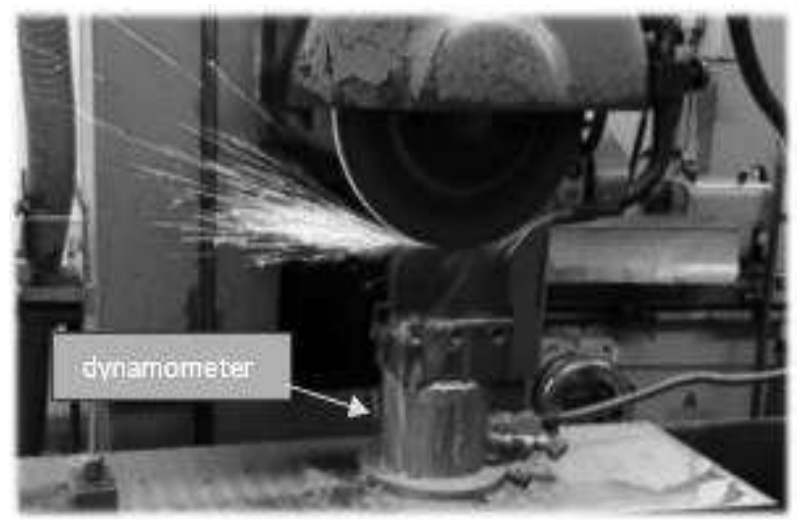

Fig. 1 The sample grinding by the grinder BPH 21 NA

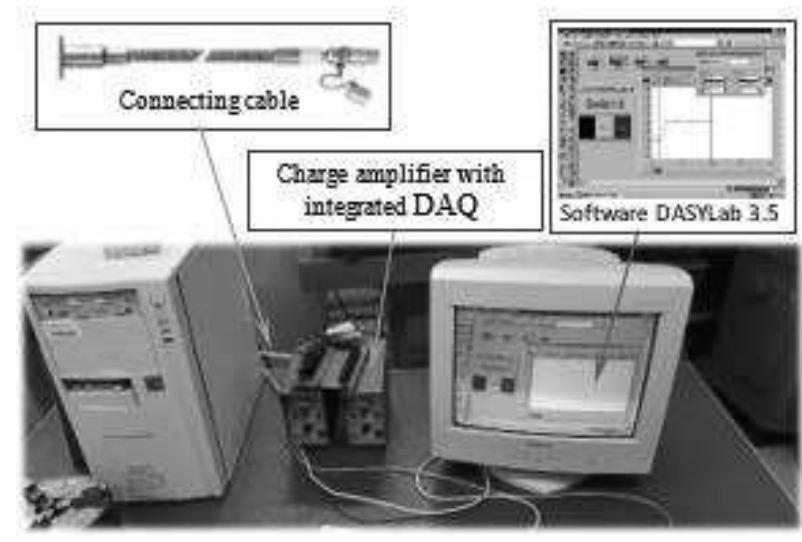

Fig. 2 The measurement of components of the cutting force by the dynamometer

The harder and measured material is, the higher are components of cutting forces. Regarding the fact that the highest impact on grinding has the component of the cutting force $F_{c}$, we evaluated only this component of the cutting force.

Tab. 2 Measured values $F_{c}$ for Titanium VT9 - the diamond grinding wheel, $v_{c}=18 \mathrm{~m} . \mathrm{s}^{-1}, v_{f}=4 \mathrm{~m} . \mathrm{min}^{-1}$

\begin{tabular}{|c|c|c|c|c|}
\hline$a_{p}[\mathrm{~mm}]$ & 0.005 & 0.01 & 0.015 & 0.02 \\
\hline$F_{c}[\mathrm{~N}]$ & $\mathbf{1 3}$ & $\mathbf{3 0}$ & $\mathbf{5 2}$ & $\mathbf{6 7}$ \\
\hline
\end{tabular}

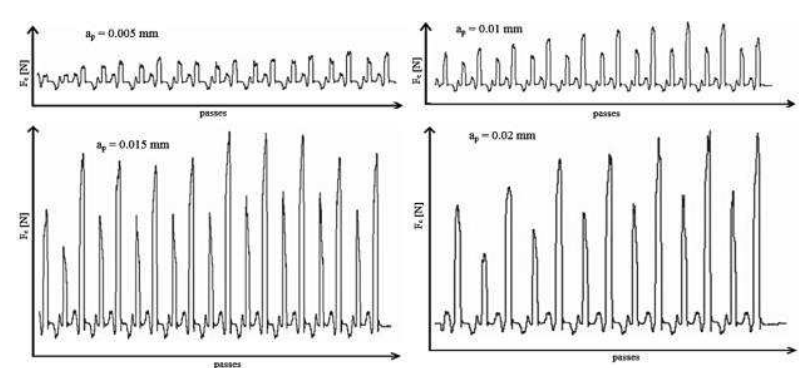

Fig. 3 The working cycle of grinding of Titanium VT9, the diamond grinding wheel, $v_{c}=18 \mathrm{~m} \cdot \mathrm{s}^{-1}, v_{f}=4 \mathrm{~m} \cdot \mathrm{min}^{-1}$ 
Tab. 3 Measured values $F_{c}$ for Titanium VT9 - the grinding wheel 5TG, $v_{c}=18 \mathrm{~m} \cdot \mathrm{s}^{-1}, v_{f}=4 \mathrm{~m} \cdot \mathrm{min}^{-1}$

\begin{tabular}{|c|c|c|c|c|}
\hline$a_{p}[\mathrm{~mm}]$ & 0.005 & 0.01 & 0.015 & 0.02 \\
\hline$F_{c}[\mathrm{~N}]$ & $\mathbf{1 9}$ & $\mathbf{3 4}$ & $\mathbf{4 3}$ & $\mathbf{5 5}$ \\
\hline
\end{tabular}

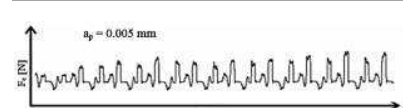
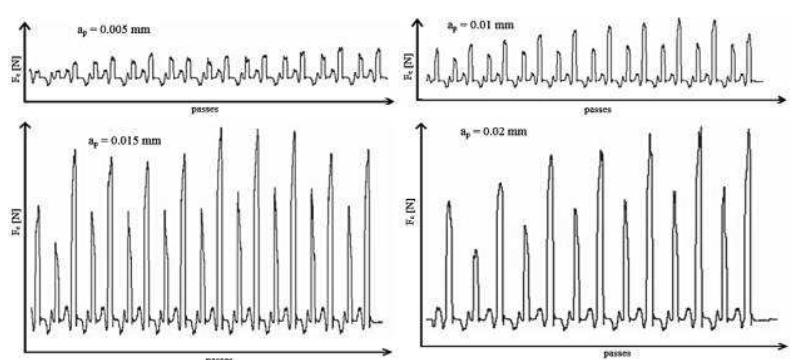

Fig. 4 The working cycle of grinding of Titanium VT9, the grinding wheel 5TG, $v_{c}=18 \mathrm{~m} . \mathrm{s}^{-1}, v_{f}=4 \mathrm{~m} \cdot \mathrm{min}^{-1}$

In Tables 2. and 3. and in records in Figures 3. and 4. one can see the measured values of the component of the cutting force $F_{c}$ after grinding by different grinding wheels. By grinding of titanium, cutting forces are markedly lower than in case of the application of the diamond grinding wheel.

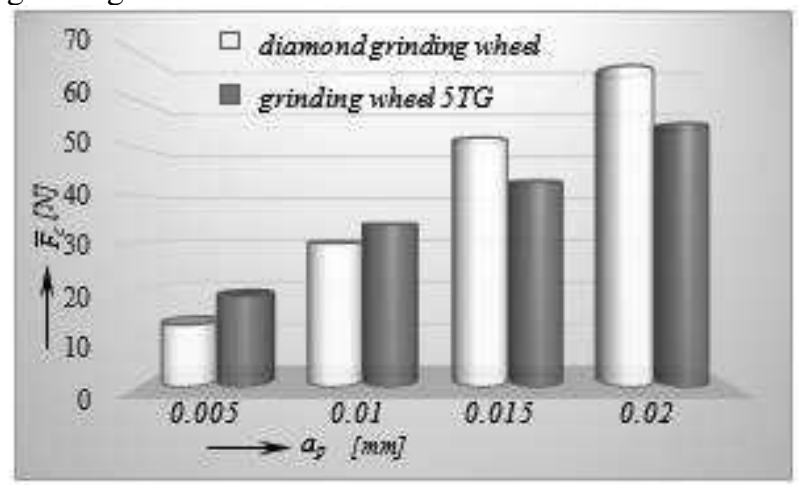

Fig. 5 The impact of $a_{p}$ on the size of the cutting force $F_{c}, v_{c}=18 \mathrm{~m} \cdot \mathrm{s}^{-1}, v_{f}=4 \mathrm{~m} \cdot \mathrm{min}^{-1}$, Emulzin $\mathrm{H}-2 \%$

From the measured data we may conclude (Fig.5.) that in case of grinding VT9 the components of the cutting force $F_{c}$ are diverse. In case of grinding by the diamond grinding wheel it is lower by small removals $(0.005$ and 0.01). However, as we can notice, in case of higher removals, the component of the cutting force is smaller by grinding with the grinding wheel 5TG. I tis caused by the fact that titanium is a hard material and there originates a lot of heat when grinding and it results in higher cutting forces $F_{c}$. Of course, also the cutting speed, cutting fluid, grain size and its hardness and porosity also has an impact to a great extent.

\section{The origin of residual stresses}

Residual stress was measured by the Proto iXRD system. The model iXRD by the company Proto (Fig. 6.) is set on the compact and portable $300 \mathrm{~W}$ control unit iXRD with integrated high-voltage supply, x-ray cooling, engine control, system electronics and display for $\mathrm{kV}, \mathrm{mA}$.

In the samples was the evaluated measurement at $a_{p}=$ $0.005 ; 0.01 ; 0.015 ; 0.02 \mathrm{~mm}$. All measurement was performed on the sample surface, so it does not reach deeper than $0.15 \mathrm{~mm}$. The reason was that in the surface layer a high compressive residual stress at lower removal takes place (finishing conditions regarding the surface) and at higher removal it changes into tensile residual stress. The material has weak thermal conductivity and there originates a high amount of heat when grinding. Compressive stresses are high, and they slightly shift to tensile stresses. The higher thermal exposition, the sooner stresses move to tensile stress.

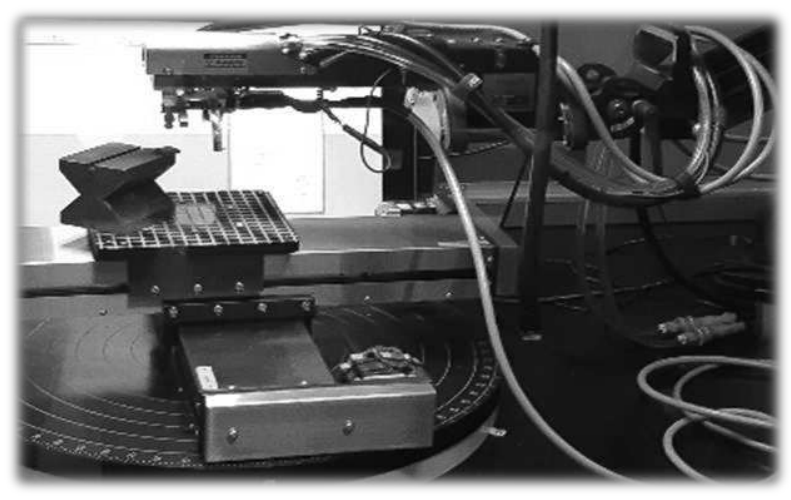

Fig. 6 The system iXRD Proto and its parts

Tab. 4 Residual stress after grinding with the grinding wheel 5TG, $v_{c}=18 \mathrm{~m} . \mathrm{s}^{-1}, v_{f}=4 \mathrm{~m} \cdot \mathrm{min}^{-1}$

\begin{tabular}{|c|c|c|c|c|}
\hline$a_{p}[\mathrm{~mm}]$ & 0.005 & 0.01 & 0.015 & 0.02 \\
\hline stress $\sigma[\mathrm{MPa}]$ & $\mathbf{5 9 0}$ & $\mathbf{7 6 6}$ & $\mathbf{7 6 5}$ & $\mathbf{8 2 3}$ \\
\hline failure $\Delta \sigma$ & $\mathbf{2 9}$ & $\mathbf{3 5}$ & $\mathbf{4 4}$ & $\mathbf{4 9}$ \\
\hline
\end{tabular}

In Table 4 we can see that we do not record any compressional stress when measuring residual stress by means of the application of the grinding wheel 5TG by the small removal $0.005 \mathrm{~mm}$. However, when we used the diamond grinding wheel by the small removal $0.005 \mathrm{~mm}$ we observe compressional stress (finishing conditions from the standpoint of the surface). Therefore, the application of the diamond grinding wheel is more suitable as tensional stress negatively affects fatigue strength and tensional stress increases it.

Tab. 5 Residual stress after grinding with the diamond grinding wheel, $v_{c}=18 \mathrm{~m} \cdot \mathrm{s}^{-1}, v_{f}=4 \mathrm{~m} \cdot \mathrm{min}^{-1}$

\begin{tabular}{|c|c|c|c|c|}
\hline$a_{p}[\mathrm{~mm}]$ & 0.005 & 0.01 & 0.015 & 0.02 \\
\hline stress $\sigma[\mathrm{MPa}]$ & $\mathbf{- 5 4}$ & $\mathbf{3 1 8}$ & $\mathbf{4 4 4}$ & $\mathbf{9 3 7}$ \\
failure $\Delta \sigma$ & $\mathbf{2 6}$ & $\mathbf{5 4}$ & $\mathbf{4 1}$ & $\mathbf{5 9}$ \\
\hline
\end{tabular}

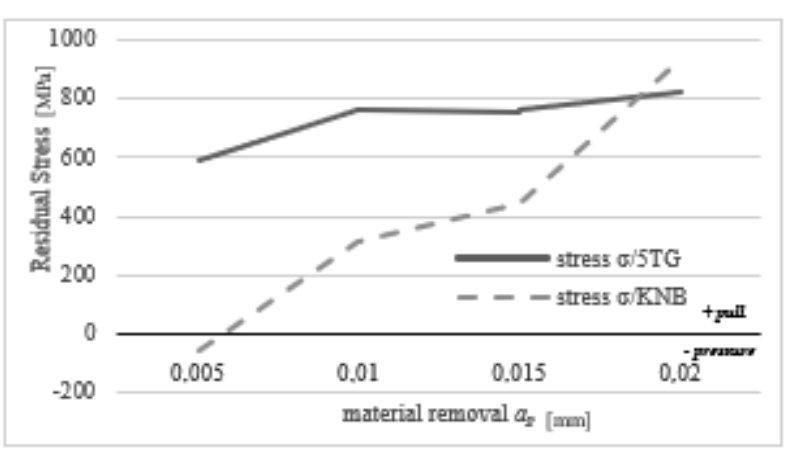

Fig. 7 Residual stress when grinding Titanium - VT9 Emulzin $\mathrm{H} 2 \%, v_{c}=18 \mathrm{~m} \cdot \mathrm{s}^{-1}, v_{f}=4 \mathrm{~m} \cdot \mathrm{min}^{-1}$ 
From the graph we can observe that it is more suitable to apply the diamond wheel to grind Titanium - VT9 by given cutting conditions. The depth of the cut most significantly affects residual stress. When grinding titanium at small depth of the cut $(0.005 \mathrm{~mm})$, there occur tensional stresses as we can see in Figure 7. When we increase the depth of the cut there occur tensional stress and in case of further increase tensional stress rises as we can see in Figure 7.

In case VT9 and the application of the diamond grinding wheel the limit of a shift of compressional stress to tensional stress moves to smaller depths of the cut 0.005 $\mathrm{mm}$. Their size, direction and distribution are affected by system vibration, cutting speed, sparking and the applied grinding wheel.

The fact that stress by higher feed was evaluated as worse according to the measurement is not so significant. They are roughing cycles followed by finishing ones. More important is the value of stresses by $0.005 \mathrm{~mm}$ and $0.01 \mathrm{~mm}$ as they are finishing cycles.

We applied the cutting fluid Emulzin $\mathrm{H} 2 \%$ that positively affects residual stress. The cutting fluid decreases cutting force and positively affects an amount of heat that originates in the spot of cutting. Thermal and mechanical properties of the machined material affect a size and distribution of residual forces after grinding. A significant role by residual stress plays also heat strength of the machined material (strength, hardness and toughness). From measurement we also can observe where there is residual stress higher in case of the diamond wheel than in case of the wheel 5TG. Moreover, contact heat is also higher in case of the diamond wheel.

\section{Surface roughness after grinding}

As titanium belongs to hard materials, when it is ground typical is an increase of components of cutting force and strain of the grinding wheel regarding heat concentration in the cutting zone. Titanium grinding is more complicated than grinding of common materials from the standpoint of a selection of cutting conditions which markedly affects surface roughness. To obtain suitable roughness parameters a lower cutting force is recommended when grinding of titanium together with small feed depths, namely $0.03 \mathrm{~mm}$.

Surface roughness after grinding was measured by the surface profile tester measuring instrument HOMMEL WERKE LV - 100, Fig. 8. To measure surface roughness of samples we used the simple software for surface measuring DASYLab 8.0.

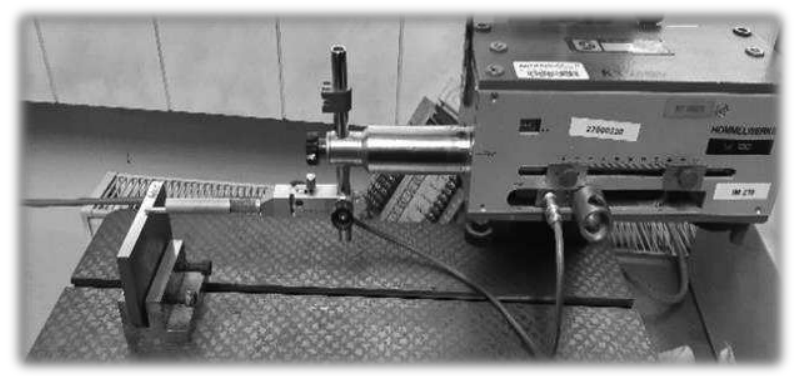

Fig. 8 The surface profile tester measuring instrument HOMMEL WERKE LV - 100

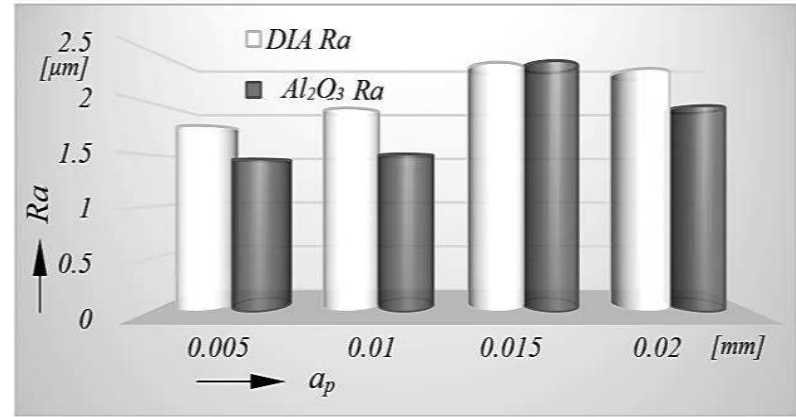

Fig. 9 Graph of dependence of Ra when grinding Titan VT9, $v_{c}=18 \mathrm{~m} . \mathrm{s}^{-1}, v_{f}=4 \mathrm{~m} . \mathrm{min}^{-1}$

\section{The graph of dependence of Ra by grinding of Tita-} nium VT9

From measured values in Figure 9 we can see that it is more suitable to use the grinding wheel 5TG from the standpoint of surface roughness. Surface roughness in case of grinding by the diamond grinding wheel is worse. It is caused by the number of grains. The number of grains contributing to a removal of the same volume of metal is much lower than in case of the wheel $\mathrm{Al}_{2} \mathrm{O}_{3}$. Grinding grains of the diamond wheel are of a different shape compared to grains of 5TG as well as other mechanical, thermal and frictional properties. We can observe that in captured chips in their thickness and shapes.

It is necessary to mention that grinding of titanium alloys without fluids can cause decreased quality of the ground area, low productivity of grinding, a high consumption of abrasives and a formation of residues on the grinding wheel. The emulsion forms a barrier between the ground grain and ground material and thus decreases negative phenomena by grinding.

\section{Conclusion}

Machining of titanium alloys is still complex despite fast technology development. There originate still new issues that cause a machined surface of bad quality (roughness, tensional stress, dimensional inaccuracies). These are also resulting of cutting forces and heat formation caused by machining. Due to heat there originate high residual stresses and that affects surface quality. Despite all above stated, many of the issues are easy to avoid and eliminate by means of experimental measurements, applications of different grinding wheels and parameters.

Experimental verifications were aimed at grinding of the material VT9 by the grinding wheel from 5TG grains and the diamond wheel. They show surface roughness, cutting forces and residual stress that directly affect integrity of the machined surface.

As we can observe in the taken experimental measurement, when grinding the specified material by the diamond wheel we obtained lower values of the component of the cutting force $F_{c}$ by lower values $a_{p}$ and the lowest residual stress which resulted in an application of the cutting fluid Emulzin - $\mathrm{H} 2 \%$ and it has a positive impact on heat transfer from the cutting spot. However, when applied the grinding wheel from 5TG grains we reached lower values of $F_{c}$ by higher tested values $a_{p}$. Surface roughness was better in case of this wheel by all applied 
removals.

From the above-stated we may assume that by the given cutting conditions is more suitable to apply the wheel 5TG by $a_{p}=0.015$ and 0.02 . By $a_{p}=0.005$ a 0.01 is very important to define which from the integrity surface parameters is significant for a given product.

\section{Acknowledgement}

The article was made under support grant project KEGA 022ŽU-4/2017 Implementation of on-line education in the area of precise technologies with an impact on educational process to increase skills and flexibility of students of engineering fields of study.

\section{References}

[1] ZHENG LI 1 \& WENFENG DING1 \& CHAOJIE LIU1 \& HONGHUA SU1...Grinding performance and surface integrity of particulate-reinforced titanium matrix composites

[2] PETRŮ, J. - SCHIFFNER, J. - ZLÁMAL, T. ČEP, R. - KRATOCHVÍL, J. - STANČEKOVÁ, D. (2016). Chip breaker of cutting tool and its influence at dynamic force of machining titanium alloy TI(6)AL(4)V. In METAL 2016 Conference Procedings of the 25 International Conference on Metallurgy and Materials, Conference Proceedings, pp. 855-860

[3] ULUTAN D, OZEL T (1994) Machining induced surface integrity in titanium and nickel alloys: a review. Int J Mach ToolsManuf 51(3), 250-280.

[4] JACKSON MJ, DAVIS CJ, HITCHINER MP, MILLS B (2001) High-speed grinding with CBN grinding wheels-applications and future technology. J Mater Process Technol 110(1):78-88.

[5] YAO CF, JIN QC, HUANG XC, WU DX, REN JX, ZHANG DH (2013) Research on surface integrity of grinding Inconel 718. Int $\mathrm{J} A d v$ Мanufacturing Technology 65(5):1019-1030.

[6] BIGERELLE, M.; GAUTIER, A.; HAGEGE, B.; FAVERGEON, J.; BOUNICHANE, B. (2009). Roughness characteristic length scales of belt finished surface. J. Mater. Process. Technol., 209, 6103-6116.
[7] BIGERELLE, M.; GAUTIER, A.; HAGEGE, B. (2008). Mechanical modelling of micro-scale abrasion in superfinish belt grinding. Tribol. Int, 41, 992-1001.

[8] BHAUMIK, S.K.; SUJATA, M.; VENKATASWAMY, M.A. (2008). Fatigue failure of aircraft components. Eng. Fail. Anal., 15, 675-694.

[9] YI HE, GUIJIAN XIAO *, WEI LI AND YUN HUANG Residual Stress of a TC17 Titanium Alloy after Belt Grinding and Its Impact on the $\mathrm{Fa}$ tigue Life. Materials in creep-feed grinding

[10] CZÁN, A., SAJGALÍK, M., HOLUBJAK, J., KOURIL, K. (2013). Studying of cutting zone when finishing titanium alloy by application of multifunction measuring system. Manufacturing Technology, Vol. 13, Issue 4, pp. 428-431

[11] NOVOTNÝ, J., LYSONKOVA, I., NAPRSTKOVA, N., MICHNA, S. (2017) Research of application possibilities of selected mechanically alloyed metal powders, In Manufacturing Technology, vol. 17, no. 5, p. 811-815

[12] PAGÁČ, M., MALOTOVÁ, Š., SADÍLEK, M., PETRŮ, J., ZLÁMAL, T., KRATOCHVÍL, J. (2016). Influence of effective milling strategies on the residual stress. METAL 2016 - 25th Anniversary International Conference on Metallurgy and Materials, Conference Proceedings 2016, pp. 819824

[13] MITAL, D., ZAJAC, J., HATALA, M., MICHALIK, P., DUPLAK, J. (2014). Identification of internal residual stress of steel after milling by ultrasound. Manufacturing Technology, Vol. 14, Issue 4, pp.573-578

[14] MLYNEK, R., Titanium, cosmic age metal. On line: https://korzar.sme.sk/c/ 4401137/titan-kovkozmickeho-veku.html

[15] BIBUS SLOVAKIA, Titanium and titanium alloys. - https://www.bibus.sk/ 